\title{
Evaluation of Knowledge and Attitude of Practising Dentists in Oman towards Minimal Intervention (MI) Management of Dental Caries - A National Survey
}

\section{Thillaikkarasi Viswapurna ${ }^{1 *}$, Laila AlJadidi $^{2}$, PS Viswapurna ${ }^{3}$ and Mohammad Zeinalddin ${ }^{4}$}

${ }^{1}$ Lecturer, Oman Dental College, Sultanate of Oman

${ }^{2}$ Senior Consultant Orthodontist, Al Nahda Hospital, Sultanate of Oman

${ }^{3}$ Senior Lecturer and Course Director, Department of Orthodontics, Oman Dental

College, Sultanate of Oman

${ }^{4}$ Craniofacial Orthodontist, Mohammad Orthodontic Centre - Senior lecturer and

Course Coordinator, Department of Orthodontics, Oman Dental College, Sultanate

of Oman

*Corresponding Author: Thillaikkarasi Viswapurna, Lecturer, Oman Dental College,

Sultanate of Oman.
Received: June 01, 2021

Published: June 23, 2021

(C) All rights are reserved by Thillaikkarasi

Viswapurna., et al.

\section{Abstract}

Advances in knowledge:

1. This study will provide an insight into the knowledge and attitude of general practitioners in Oman towards adopting MI principles of caries management.

2. It will guide towards improving the implementation of concepts of minimally invasive dentistry.

Application to patient care:

1. This article provides the general dentists with a recommendation as to which aspects of MID are being overlooked and not followed and hence will improve the implementation of the same.

2. Incorporation into dental education in a more practical manner will benefit patient care.

Keywords: Minimal; Intervention; Dentistry; Caries; Oman

\section{Introduction}

Dental caries is a pandemic disease that is associated with pain in the advanced stages. It is the most common reason for patient's seeking dental care. The prevalence of the disease in Oman has been well documented via quantitative studies in the past $[1,2]$.

The conventional mode of treatment pushes the tooth into a continuous cycle of repeated restorations which decreases the longevity of the tooth. Minimal Intervention Dentistry advocates a biological approach in treating dental caries with the primary focus on eliciting the etiological factors and eliminating them. Removal of the irreversibly damaged tissue and its replacement with contemporary restorative materials should be carried out alongside the elimination of the causative factors to restore the diseased tooth material to normal form.

Progressive developments in material science and increased knowledge on the aetiology and pathophysiology of the disease 
have immensely influenced the development of a contemporary blueprint for caries management. Minimum intervention and minimally invasive techniques are often misunderstood to be the same. However, they vary in their philosophy [3]. The former aims at disease elimination by identifying and eliminating the aetiology of the dental disease with the help of data gathered through detailed history taking, clinical examinations and special tests. A preventive care plan is formulated if the carious lesions are identified to be not cavitated. Risk assessment aided diagnosis facilitates the formulation of tailor-made care plans for patients to suit their individual needs. Irreversibly damaged tissue, when identified, is removed using minimally invasive techniques, to be replaced with adhesive biomimetic restorative materials to ensure optimum function and aesthetics. Adopting minimum intervention principles and minimally invasive techniques at the clinical practice will aid in eliminating dental caries [3].

Advancements in the field of dental restorative materials and an increase in knowledge of disease initiation and progression have paved the way for the development of preventive and minimally invasive strategies in treating and preventing dental caries. The minimally invasive model synthesizes knowledge of the disease process into a simple conceptual model using new technologies [4-6]. Minimally Invasive Dentistry emphasizes conservative caries management strategies resulting in less destruction of tooth structure, a deviation of the traditional GV Black's restorative principles [7]. It advocates the use of adhesive dental materials that are associated with conservative cavity preparations because these materials do not require mechanical retention; instead, they rely on the adhesive process to bond to the tooth structure $[8,9]$.

The MI care plan for caries management has four phases. Phase 1 focuses on early diagnosis which is arrived at by cumulative analysis of data gathered via verbal history, intraoral examination radiographs and sensibility test results. Once diagnosed, phase 2 involves categorising patients to receive standard or active care based on their caries risk assessment. The next phase is the restorative phase, where minimally invasive techniques along with adhesive restorative materials are used to restore irreversibly damaged dental hard tissue. Once the restorative care is completed, a patient-centred tailor-made recall schedule is formulated in phase 4. Minimally invasive dentistry revolves around the core principle of maximum conservation of the affected tissues, which can recover and recuperate to normal health and function.

This research survey aimed at evaluating the extent to which MI (Minimum Intervention) concepts of treating dental caries were popular among practising dentists in Oman. Therefore, the study aimed to evaluate the knowledge and attitude of general practitioners in Oman towards adopting MI principles of caries management.

\section{Aim of the Study}

To evaluate the knowledge and attitude of practising dentists in Oman towards Minimal Intervention Management of Dental Caries.

\section{Methodology}

The study designed proposed for this research work was a cross-sectional survey.

\section{Inclusion and exclusion criteria}

Omani practitioners who were actively involved in treating dental caries were included in the study. Specialists, non-practising dentists, undergraduate and postgraduate students were excluded from the study. Data collection for qualitative analysis was done via an electronic Questionnaire. The participation in this study was completely voluntary and the data collected from the research recruits were securely stored and anonymity was maintained throughout the study process and during publication of the results.

The questionnaire designed for this study was a modified version of a pre-validated questionnaire used in two other studies conducted in the year 2010 [10] in the United States and 2016 in Riyadh, Saudi Arabia [3].

A pilot study was conducted after obtaining ethical approval and appropriate amendments were made to the questionnaire based on the results of the pilot study. The participants included in the pilot study were excluded from the main study to avoid bias.

\section{Study procedure}

Statistical data suggested that there are 726 practising dentists in Oman. Sample size was calculated using the Raosoft ${ }^{\mathrm{TM}}$ sample size calculator with the acceptable margin of error set to $7.23 \%$. The sample size was fixed to 110 respondents. The questionnaire was sent as an email to all reachable dentists in Oman and among those who responded, 110 dentists who fit the inclusion criteria were selected.

After obtaining approval from the Al Nadha Hospital Research Committee, Sultanate of Oman, the research recruits were given an information leaflet, which explained in detail the research in simple language and the expected compliance from the subjects. Participants who gave consent voluntarily were included in the 
Evaluation of Knowledge and Attitude of Practising Dentists in Oman towards Minimal Intervention (MI) Management of Dental Caries - A National Survey

study and were asked to answer an e-questionnaire. The obtained results were subjected to statistical analysis using software SPSS version 20 .

\section{Results}

Table 1A shows the descriptive statistics showing the number and percentage of responses of study participants for the questionnaire. $72.7 \%$ of the respondents were female and the rest were male. $42 \%$ of the respondents were practising for less than 5 years. $88 \%$ of the respondents said that they were familiar with the principles of minimum intervention dentistry and $87 \%$ said that caries management was a part of their everyday practice. But only $66 \%$ recorded the diet history and fluoride history of their patients and $89 \%$ did not perform a saliva test in their clinic. Only $53 \%$ assessed the caries risk of their patients.

\begin{tabular}{|c|c|c|c|}
\hline Variable & Category & No & $\%$ \\
\hline \multirow{2}{*}{ What is your gender? } & Male & 30 & 27.3 \\
\hline & Female & 80 & 72.7 \\
\hline \multirow{2}{*}{ Are you a practicing dentist in Oman? } & No & 2 & 1.8 \\
\hline & Yes & 108 & 98.2 \\
\hline \multirow{3}{*}{ How long have you been in clinical practice? } & Less than 5 years & 46 & 41.8 \\
\hline & 5-10 years & 21 & 19.1 \\
\hline & More than 10 years & 43 & 39.1 \\
\hline \multirow{4}{*}{ Who are you employed with? } & Corporate hospitals & 11 & 10.0 \\
\hline & Ministry of Health & 43 & 39.1 \\
\hline & Others & 37 & 33.6 \\
\hline & Self-employed & 19 & 17.3 \\
\hline \multirow{3}{*}{ Are you familiar with the principles of Minimum Intervention Dentistry? } & No & 5 & 4.5 \\
\hline & Yes & 97 & 88.2 \\
\hline & Not sure & 8 & 7.3 \\
\hline \multirow{3}{*}{ Is caries management a part of your everyday practice? } & No & 13 & 11.8 \\
\hline & Yes & 96 & 87.3 \\
\hline & Still not working & 1 & .9 \\
\hline \multirow{5}{*}{$\begin{array}{l}\text { Which of the factors mentioned below in your opinion will influence } \\
\text { caries management protocol and prognosis? }\end{array}$} & Diet & 4 & 3.6 \\
\hline & Brushing habit & 3 & 2.7 \\
\hline & Fluoride & 1 & .9 \\
\hline & Quantity and quality of saliva & 1 & .9 \\
\hline & All of the above & 101 & 91.8 \\
\hline \multirow{3}{*}{ Do you record diet history and fluoride history of your patients? } & Always & 21 & 19.1 \\
\hline & At times when appropriate & 73 & 66.4 \\
\hline & Never & 16 & 14.5 \\
\hline \multirow{3}{*}{ Do you perform a saliva test in your clinic? } & No & 98 & 89.1 \\
\hline & Yes & 4 & 3.6 \\
\hline & 2 & 8 & 7.3 \\
\hline \multirow{4}{*}{ Do you assess the caries risk of your patients? } & No & 11 & 10.0 \\
\hline & Yes & 59 & 53.6 \\
\hline & 2 & 36 & 32.7 \\
\hline & I don't know to risk assess & 4 & 3.6 \\
\hline
\end{tabular}

Table 1A: Descriptive statistics showing number and percentage of responses of study participants for questionnaire. 
Evaluation of Knowledge and Attitude of Practising Dentists in Oman towards Minimal Intervention (MI) Management of Dental Caries - A National Survey

Table 1B shows the continuation of the descriptive statistics showing the number and percentage of responses of study participants for the questionnaire. $88.2 \%$ of the respondents think that assessing the caries risk of their patients will influence the care plan. $76.4 \%$ of the respondents did not use magnification (loupes) for caries detection and cavity preparation. 93.6\% said that they used primarily radiographs for caries detection but only a mini- mal number used advanced techniques like laser, Diagnodent etc. $53.6 \%$ used a sharp probe for caries detection and $43.6 \%$ used a blunt probe. $65.5 \%$ used burs and handpiece to perform caries excavation and $26.4 \%$ used only hand instruments. $94.5 \%$ believed they adopted minimally invasive cavity designs during cavity preparation while $88.2 \%$ practised selective caries removal.

\begin{tabular}{|c|c|c|c|}
\hline Variable & Category & No & $\%$ \\
\hline \multirow{3}{*}{$\begin{array}{l}\text { Do you think that assessing the caries risk of your patients } \\
\text { will have an influence on your care plan? }\end{array}$} & No & 2 & 1.8 \\
\hline & Yes & 97 & 88.2 \\
\hline & Not sure & 11 & 10.0 \\
\hline \multirow{3}{*}{$\begin{array}{l}\text { Do you use magnification (loupes) for caries detection and } \\
\text { cavity preparation? }\end{array}$} & No & 84 & 76.4 \\
\hline & Yes & 20 & 18.2 \\
\hline & 2 & 6 & 5.5 \\
\hline \multirow{6}{*}{$\begin{array}{l}\text { Do you use any one of the techniques listed below for caries } \\
\text { detection? }\end{array}$} & LASER / Diagnodent & 1 & .9 \\
\hline & Radiographs & 103 & 93.6 \\
\hline & $\begin{array}{l}\text { Radiograph, fiber optic, elastic separator then } \\
\text { direct checking }\end{array}$ & 1 & .9 \\
\hline & Clinical examination & 1 & .9 \\
\hline & Fiber optic & 3 & 2.7 \\
\hline & dry tooth and light $+/-2$ & 1 & .9 \\
\hline \multirow{5}{*}{$\begin{array}{l}\text { Which of the following hand instruments do you use to detect } \\
\text { caries? }\end{array}$} & Sharp Probe & 59 & 53.6 \\
\hline & Blunt probe & 48 & 43.6 \\
\hline & $\begin{array}{l}\text { Blunt to remove plaque and food debris then dry } \\
\text { with air and light }\end{array}$ & 1 & .9 \\
\hline & Scalar tip & 1 & .9 \\
\hline & Nil & 1 & .9 \\
\hline \multirow{6}{*}{$\begin{array}{l}\text { What instruments do you use to perform caries excavation? } \\
\text { (if you employ multiple techniques, please select the appro- } \\
\text { priate options) }\end{array}$} & Burs and hand piece & 72 & 65.5 \\
\hline & Hand instruments & 29 & 26.4 \\
\hline & Excavator & 1 & .9 \\
\hline & LASER & 2 & 1.8 \\
\hline & Burs, handpiece and hand instrments & 5 & 4.5 \\
\hline & Hand excavation, burs and handpiece & 1 & .9 \\
\hline \multirow{3}{*}{$\begin{array}{l}\text { Do you adopt minimally invasive cavity designs during cavity } \\
\text { preparation? }\end{array}$} & No & 1 & .9 \\
\hline & Yes & 104 & 94.5 \\
\hline & I have never heard of such design & 5 & 4.5 \\
\hline \multirow{3}{*}{ Do you practice selective caries removal? } & No & 4 & 3.6 \\
\hline & Yes & 97 & 88.2 \\
\hline & I have never heard of such design & 9 & 8.2 \\
\hline
\end{tabular}

Table 1B: Descriptive statistics showing number and percentage of responses of study participants for questionnaire. 
Evaluation of Knowledge and Attitude of Practising Dentists in Oman towards Minimal Intervention (MI) Management of Dental Caries - A National Survey

Table 1C shows the continuation of the descriptive statistics showing the number and percentage of responses of study participants for the questionnaire. $12.7 \%$ felt that minimally invasive cavity preparation techniques will negatively affect the retention of the restoration. The perception of the rates of the effectiveness of few techniques in treating dental caries such as atraumatic restorative treatment, sandwich technique, remineralisation with fluoride varnish, paste/rinses and CPP ACP (Recaldent) were assessed and are presented in the table. Unfortunately, 31.8\% did not have a fixed recall schedule for their patients.

\begin{tabular}{|c|c|c|c|}
\hline Variable & Category & No & $\%$ \\
\hline \multirow{3}{*}{$\begin{array}{l}\text { Do you think minimally invasive cavity preparation techniques will negatively affect the } \\
\text { retention of the restoration? }\end{array}$} & No & 79 & 71.8 \\
\hline & Yes & 14 & 12.7 \\
\hline & Not sure & 17 & 15.5 \\
\hline \multirow{4}{*}{$\begin{array}{l}\text { Rate the effectiveness of the following techniques in treating dental caries: [Atraumatic } \\
\text { restorative treatment] }\end{array}$} & Ineffective & 6 & 5.5 \\
\hline & effective & 70 & 63.6 \\
\hline & Very effective & 22 & 20.0 \\
\hline & Dont know & 12 & 10.9 \\
\hline \multirow{4}{*}{$\begin{array}{l}\text { Rate the effectiveness of the following techniques in treating dental caries: [Sandwich } \\
\text { technique] }\end{array}$} & Ineffective & 5 & 4.5 \\
\hline & effective & 79 & 71.8 \\
\hline & Very effective & 21 & 19.1 \\
\hline & Dont know & 5 & 4.5 \\
\hline \multirow{4}{*}{$\begin{array}{l}\text { Rate the effectiveness of the following techniques in treating dental caries: } \\
\text { [Remineralisation with fluoride varnish] }\end{array}$} & Ineffective & 10 & 9.1 \\
\hline & effective & 67 & 60.9 \\
\hline & Very effective & 28 & 25.5 \\
\hline & Dont know & 5 & 4.5 \\
\hline \multirow{4}{*}{$\begin{array}{l}\text { Rate the effectiveness of the following techniques in treating dental caries: } \\
\text { [Remineralisation with fluoride paste/rinses] }\end{array}$} & Ineffective & 14 & 12.7 \\
\hline & effective & 74 & 67.3 \\
\hline & Very effective & 15 & 13.6 \\
\hline & Dont know & 7 & 6.4 \\
\hline \multirow{4}{*}{$\begin{array}{l}\text { Rate the effectiveness of the following techniques in treating dental caries: } \\
\text { [Remineralisation with CPP ACP (Recaldent)] }\end{array}$} & Ineffective & 4 & 3.6 \\
\hline & effective & 62 & 56.4 \\
\hline & Very effective & 20 & 18.2 \\
\hline & Dont know & 24 & 21.8 \\
\hline \multirow[b]{3}{*}{ Do you have a fixed recall schedule for all you patients? } & No & 35 & 31.8 \\
\hline & Yes & 71 & 64.5 \\
\hline & $\begin{array}{c}\text { I never advise a recall, } \\
\text { patients come back } \\
\text { when they have a } \\
\text { problem }\end{array}$ & 4 & 3.6 \\
\hline
\end{tabular}

Table 1C: Descriptive statistics showing number and percentage of responses of study participants for questionnaire.

\section{Discussion}

Managing dental caries is quite challenging and this could be attributed to the multifactorial aetiology of the disease. Ideal disease management strategies should focus on increasing the longevity of the diseased tooth by halting the disease process and restoring the lost tooth structure to normal form and function. This could be accomplished by shifting the care from a surgical approach to a more biological approach. This study helped identify the most popular 
dental caries management strategy among dentists in Oman and in planning future educational programmes which would aid in familiarising the dentists with contemporary evidence-based concepts.

Since $72.7 \%$ of the respondents in this study were female and the rest were male, we could not compare the differences in the responses between genders due to the unequal distribution. In another study, age and gender did not seem to affect the knowledge possessed about MI dentistry [3]. In our study, 39.1\% of the practitioners were practising for more than ten years, and $88.2 \%$ of the total sample felt that they were familiar with the principles of Minimum Intervention Dentistry. In another study conducted in Riyadh and AlKharj cities of Saudi Arabia, it was found that more than half (51.5\%) of the respondents either had no knowledge or only possessed little knowledge about MID [3]. Hence it shows that Omani dentists have a higher level of knowledge about MID concepts compared to dentists from Saudi. In a study among dental practitioners in Karnataka, India, $97 \%$ of respondents were aware of the principles of preventive dentistry and $90.7 \%$ of the respondents possessed knowledge about the re-mineralization of initial lesions instead of using surgical procedures on the prognosis of the caries [11].

In this study, $87.3 \%$ of the sample said that caries management was a part of their everyday practice and $91.8 \%$ of the sample studied professed that they were aware of the multifactorial aspects in caries management protocol and prognosis. This showed a high level of awareness among them.

Caries risk assessment should be done for all patients. Yet in our study, only $53.6 \%$ of the sample performed the same. Also, $89.1 \%$ of the sample did not perform a saliva test in their clinic. Only $66 \%$ recorded the diet history and fluoride history of their patients. Hence there was a mismatch in the perception and actual implementation of MID protocols. This could be because a majority of the sample were practising for more than ten years and hence their dental education would not have sensitized them to these protocols. It is evident that although the concepts of MID are not very recent, yet these need to be incorporated completely into the curriculum of dental schools across the globe.

In our study, $76.4 \%$ of the respondents did not use magnification (loupes) for caries detection and cavity preparation. Respondents with MID training are expected to use higher magnification like loupes as well new diagnostic methods for caries detection but lack of availability of such equipment or a lack in the adoption of the principles of MID may be a reason. Nevertheless, newer methods of caries detection have shown to be less invasive and of good diagnostic value $[12,13]$.

American Dental Association recommends limiting the use of radiography and implementing appropriate radiation control procedures [14]. In our study, 93.6\% said that they used primarily radiographs for caries detection but only a minimal number used advanced techniques like laser, Diagnodent etc. Also, 53.6\% used a sharp probe for caries detection and $43.6 \%$ used a blunt probe. The use of sharp explorer was related to the training in MID. The use of a sharp explorer as a diagnostic tool for primary caries diagnosis should be discontinued as it may cause some harm and fails to provide a significant diagnostic benefit [15].

These findings again show a discrepancy in the knowledge and attitude of our study population regarding caries detection methods.

In our study, $65.5 \%$ used burs and handpiece to perform caries excavation and $26.4 \%$ used only hand instruments. $94.5 \%$ believed they adopted minimally invasive cavity designs during cavity preparation while $88.2 \%$ practised selective caries removal. Also, the majority of the respondents believed that MID protocols like Atraumatic restorative treatment, Sandwich technique, Remineralisation with fluoride varnish, fluoride paste/rinses and CPP ACP (Recaldent) were effective.

Minimally invasive treatment modalities in caries management have successfully evolved, as a result of effective understanding of the caries process and the advancement in the adhesive restorative materials. As a consequence, GV Black's surgical model is progressively being replaced with the contemporary MI model. Quantum leap in technology has created a wider platform for patients to gain information on contemporary elements of dental care. Minimum intervention dentistry advocates evidence-based contemporary patient-centred management strategies that not only promotes conservation of affected dental hard tissues but also increases the prognosis, which makes its incorporation into clinical practice quintessential.

\section{Conclusion}

This survey helped in assessing the popularity of Minimum Intervention concepts of caries among dentists in Oman and also in planning future continuing education programmes on MI caries management. It was found that although the respondents were 
aware of the concepts and advantages of MID, the actual implementation into practice was lacking.

\section{Acknowledgement}

The author would like to thank Avijit Banerjee, Professor of Cariology and Operative Dentistry and Professor DYD Samarawickrama for their valuable assistance and Prof. Prashantha G. Shivamurthy for statistics management (Contributions that need acknowledgement but do not justify authorship).

\section{Bibliography}

1. Al-Ismaily M., et al. "The oral health status of Omani 12-yearolds--a national survey". Community Dentistry and Oral Epidemiology 24.5 (1996): 362-363.

2. Al-Ismaily M., et al. "The progression of dental disease in Omani schoolchildren". International Dental Journal (2004): 409-410.

3. Shah AH., et al. "Knowledge and attitude among general dental practitioners towards minimally invasive dentistry in Riyadh and AlKharj". Journal of Clinical and Diagnostic Research (2016): 90-94.

4. Uskoković $\mathrm{V}$ and Bertassoni LE. "Nanotechnology in dental sciences: Moving towards a finer way of doing dentistry". Materials (2010): 1674-1691.

5. Banerjee A and Doméjean S. "The Contemporary Approach to Tooth Preservation: Minimum Intervention (MI) Caries Management in General Practice". Primary Dental Journal (2013): 30-37.

6. Featherstone JDB and Doméjean S. "Minimal intervention dentistry: Part 1. from "compulsive" restorative dentistry to rational therapeutic strategies". British Dental Journal (2012): 441445 .

7. Wolff MS., et al. "A 100-year journey from GV Black to minimal surgical intervention". Compendium of Continuing Education in Dentistry (2007): 130-152.

8. Summitt JB. “Conservative cavity preparations". Dental clinics of North America (2002): 171-184.

9. Peters MC and McLean ME. "Minimally invasive operative care. II. Contemporary techniques and materials: an overview". The Journal of Adhesive Dentistry (2001): 17-31.
10. Gaskin EB., et al. "Knowledge, attitudes, and behaviors of federal service and civilian dentists concerning minimal intervention dentistry". Military Medicine (2010).

11. Bhate P., et al. "Assessment of knowledge, attitude, and practice regarding preventive options in oral care among dentists in Davangere city, Karnataka: A cross-sectional study". Dental and Medical Research (2015).

12. Neuhaus KW., et al. "Impact of different magnification levels on visual caries detection with ICDAS”. Journal of Dentistry (2015): 1559-1564.

13. Karlsson L. "Caries Detection Methods Based on Changes in Optical Properties between Healthy and Carious Tissue". International Journal of Dentistry (2010).

14. American Dental Association Council on Scientific Affairs. "The use of dental radiographs: update and recommendations". Journal of the American Dental Association 137.9 (2006): 13041312.

15. Doméjean-Orliaguet S., et al. "Caries management decision: Influence of dentist and patient factors in the provision of dental services". Journal of Dentistry (2009): 827-834.

\section{Volume 5 Issue 7 July 2021 \\ (C) All rights are reserved by Thillaikkarasi Viswapurna., et al.}

